\title{
LISCIC/PETROFER PROBE TO INVESTIGATE REAL INDUSTRIAL HARDENING PROCESSES AND SOME FUNDAMENTALS DURING QUENCHING OF STEEL PARTS IN LIQUID MEDIA
}

\author{
Nikolai Kobasko \\ Intensive Technologies Ltd \\ 68/1 Peremohy ave., Kyiv, Ukraine, 03113 \\ nkobasko@gmail.com \\ Bozidar Liscic \\ University of Zagreb \\ 5 Ivana Lucica, Zagreb, Croatia, 10002 \\ Bozidar.liscic@fsb.hr
}

\begin{abstract}
In the paper some unusual processes are considered during quenching such as self-regulated thermal process when metallic probe is covered by insulating polymeric layer, oscillation of temperature in surface layers of probe, creation a "shoulder" when quenching in polymer solution, possibility to perform austempering process just in cold liquids. Above mentioned processes build a basis for the new intensive quenching technologies and can bring a great benefit for heat treating industry when further carefully investigated. It is shown that initial temperature gradients, which cannot be governed by classical law of Fourier, can be tested by Liscic/Petrofer probe, etc. The paper discusses how organize such international investigation to satisfy contemporary practical needs and solve unsolved problems of science in the field of quenching. Also, the results of investigations can be used for software designing and cooling recipes development during quenching steel parts in liquid media. It makes a great progress because at preset time only cooling curves and cooling rates are available that are used for comparable purpose and cannot be used for recipes development.

Keywords: self-regulated thermal process, coating, temperature oscillation, initial temperature gradients, modified law of Fourier, database development.
\end{abstract}

\section{Introduction}

For the first time Liscic/Nanmac probe and intensive quenching processes were discussed together at the international conference on Heat Treating Processes held in Kiev in 1988. Prof. Liscic introduced to the audience his Liscic/Nanmac probe with three tiny thermocouples which were instrumented on the surface of $50 \mathrm{~mm}$ probe made of AISI 304 stainless steel, at the distance $1.5 \mathrm{~mm}$ below surface and in the center of probe which was $200 \mathrm{~mm}$ long. The probe was produced in collaboration with the American company Nanmac Corp., Holliston, MA [1]. Investigators dealing with intensive quenching processes were exited by Liscic/Nanmac probe since they realized that the probe was an excellent tool for careful IQ processes investigations. At present time similar Liscic/Petrofer probe is available [2]. The matter is that alloy and high alloy steels are quenched in oils without interruption the cooling process. Furthermore, research institutes and universities are developing new expensive alloy steels to be slowly quenched in oils to prevent crack formation and decrease distortion.

Due to enthusiastic work of two companies IQ Technologies Inc., Akron, USA and Intensive Technologies Ltd, Kyiv, Ukraine, it has been established and introduced into the practice the next three main achievements of intensive quenching phenomena which are [3]:

- an Intensive Quenching (IQ) reduces significantly distortion and prevents crack formation during hardening of steels;

- decreasing alloy elements in steel increases service life of steel components when they are intensively quenched;

- alloy and high alloy steel can be intensively quenched by plain water or water solution of optimal concentration if cooling is interrupted at proper time. 
Due to these discoveries, situation in heat treating industry cardinally changed. Standard Inconel 600 probe is not more useful for controlling and maintaining quality of IQ processes [3-7]. The most suitable, at present time, is Liscic/Petrofer probe [2] which has to be widely used in heat treating industry. The aim of the current investigation is to show the possibility of using Liscic/Petrofer probe for liquid quenchants database development and accurate experimental review of discovered self-regulated thermal processes.

\section{Conventional quenching versus IQ-2 and IQ-3 processes}

As known, alloy and high alloy steels are quenched in oils or high concentration of polymers to prevent crack formation and distortion. As a rule, cooling in oils continues to bath temperature that is why heat transfer coefficients are not a big problem and standard Inconel 600 probe is a good tool to obtain cooling characteristics for maintaining oils within the specks quality [4]. Low distortion and elimination crack formation can be achieved by applying intensive quenching too [3]. The matter is that during intensive quenching, a martensitic structure forms quickly and uniformly in the part surface layer creating high current surface compressive stresses which act as a die minimizing part distortion and preventing part cracking [3].

Two IQ processes are currently used in heat treating practice: a batch IQ process and a single-part processing IQ method. When using the batch IQ process, known as IQ-2 method, parts are quenched in batches in IQ water tanks. When using the single-part processing IQ technique (known as IQ-3 method), parts are quenched one by one in high-velocity IQ units. Note that the IQ-2 process is a two- or three-step quenching method. The first step of cooling takes place in agitated water solution and is interrupted at a certain moment of time when the core of the parts being quenched is still hot. The parts are then cooled in the air during the second step of quenching. The part's martensitic layer is self-tempered by the heat coming from the part core. If necessary, the load can be brought back into the quench tank for the completion of the quench. This technology needs special recipes development where heat transfer coefficients are used to calculate correctly time of interruption. The essence of IQ-3 process consists in interruption intensive cooling when at the surface of steel parts maximal compressive stresses appear and optimal quenched layer is formed. To investigate properly both intensive quenching processes, Liscic/Petrofer probes can be successfully used.

\section{Austempering process in cold liquids}

In this paragraph an austempering process in cold liquids, developed in Ukraine, is considered $[8,9]$. The idea is very simple and understandable. When quenching in optimized cold liquid, surface temperature of steel part drops immediately close to saturation temperature (Table 1) and maintains at this level relatively a long time until transient nucleate boiling process is finished $[3,10]$. The reason of such behavior is inequity $\alpha_{n b}>\alpha_{\text {conv }}$ and is called self-regulated thermal process [10]. The duration of self-regulated thermal process is calculated from the equation (1) [11]:

$$
\tau_{\mathrm{nb}}=\Omega \mathrm{k}_{\mathrm{F}} \frac{\mathrm{D}^{2}}{\mathrm{a}}
$$

Here $\tau_{\mathrm{nb}}$ is duration of transient nucleate boiling process in sec; $\Omega$ is parameter depending on Biot number during convection when initial austenitizing temperature is fixed at $850{ }^{\circ} \mathrm{C} ; \mathrm{k}_{\mathrm{F}}$ is form coefficient; $D$ is size of steel part in $\mathrm{m}$; a is thermal diffusivity of a material in $\mathrm{m}^{2} / \mathrm{s}$. The essence of austempering process consists in interruption of cooling at the end of boiling mode and immediate transferring product to tempering at the temperature $\mathrm{T}_{\mathrm{sf}}>\mathrm{M}_{\mathrm{S}}$. Also, during transient nucleate boiling process $\mathrm{T}_{\mathrm{sf}}>\mathrm{M}_{\mathrm{S}}$. There are three major approaches allowing fulfilling austempering in cold liquids:

- use high concentration of water solution to increase boiling point to martensite start temperature $\mathrm{M}_{\mathrm{S}}$;

- use pressure to increase boiling point of water to martensite start temperature $\mathrm{M}_{\mathrm{S}}$;

- use polymer of inverse solubility which creates insulating layer on the surface of steel parts and maintains surface temperature at the end of nucleate boiling at the level $\mathrm{T}_{\mathrm{sf}}>\mathrm{M}_{\mathrm{s}}$. 
The most simple and reliable austempering process in cold liquid is the third approach. Its disadvantage is decreasing cooling rate during nucleate boiling due to surface insulating layer.

When film boiling is absent, surface temperature of steel parts drops almost to boiling point of liquid (Table 1).

Table 1

Time required for the surface of steel spheres of different sizes to cool to different temperatures when quenched from $875{ }^{\circ} \mathrm{C}$ in $5 \% \mathrm{NaOH}$-water solution at $20^{\circ} \mathrm{C}$ and moving at 3 feet per second $(0.914 \mathrm{~m} / \mathrm{s})$, according to French [12].

\begin{tabular}{ccccccccc}
\hline \multirow{2}{*}{ Average size } & \multicolumn{9}{c}{ Time, Sec } \\
& $\mathbf{7 0 0}^{\circ} \mathbf{C}$ & $\mathbf{6 0 0}^{\circ} \mathbf{C}$ & $\mathbf{5 0 0}^{\circ} \mathbf{C}$ & $\mathbf{4 0 0}^{\circ} \mathbf{C}$ & $\mathbf{3 0 0}^{\circ} \mathbf{C}$ & $\mathbf{2 5 0}^{\circ} \mathbf{C}$ & $\mathbf{2 0 0}^{\circ} \mathbf{C}$ & $\mathbf{1 5 0}^{\circ} \mathbf{C}$ \\
\hline $6.35 \mathrm{~mm}$ & 0.027 & 0.037 & 0.043 & 0.051 & 0.09 & 0.15 & 0.29 & 0.69 \\
$12.7 \mathrm{~mm}$ & 0.028 & 0.042 & 0.058 & 0.071 & 0.11 & 0.15 & 0.26 & 0.60 \\
$25.4 \mathrm{~mm}$ & 0.033 & 0.042 & 0.055 & 0.074 & 0.13 & 0.21 & 0.35 & 0.82 \\
$63.5 \mathrm{~mm}$ & 0.023 & 0.039 & 0.065 & 0.093 & 0.14 & 0.19 & 0.32 & 0.59
\end{tabular}

As seen from Table 1, surface temperature of $6.35 \mathrm{~mm}-63.5 \mathrm{~mm}$ spheres drops $875{ }^{\circ} \mathrm{C}$ to $150{ }^{\circ} \mathrm{C}$ practically for the same time that is very important when developing austempering processes in cold liquids. Also, Table 1 shows that film boiling is completely absent.

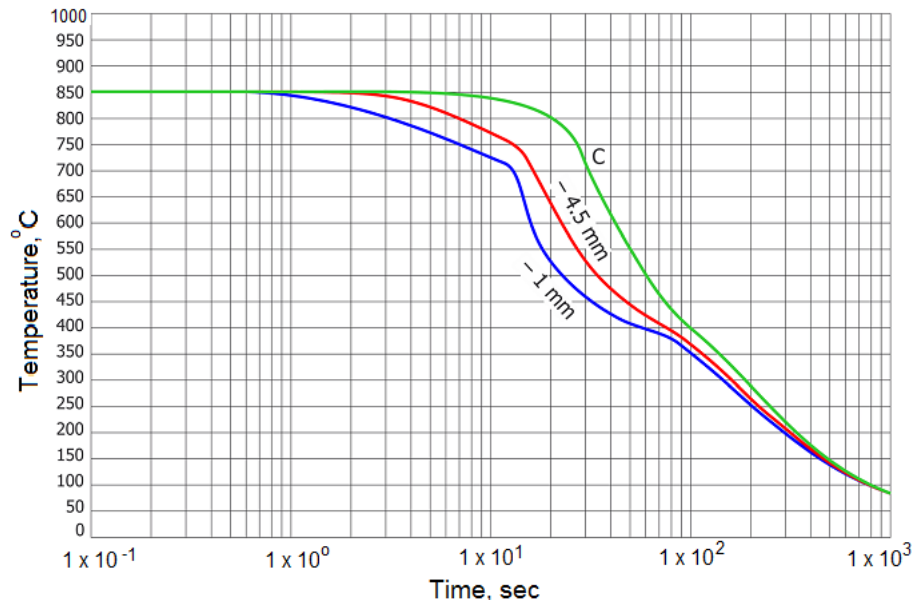

a

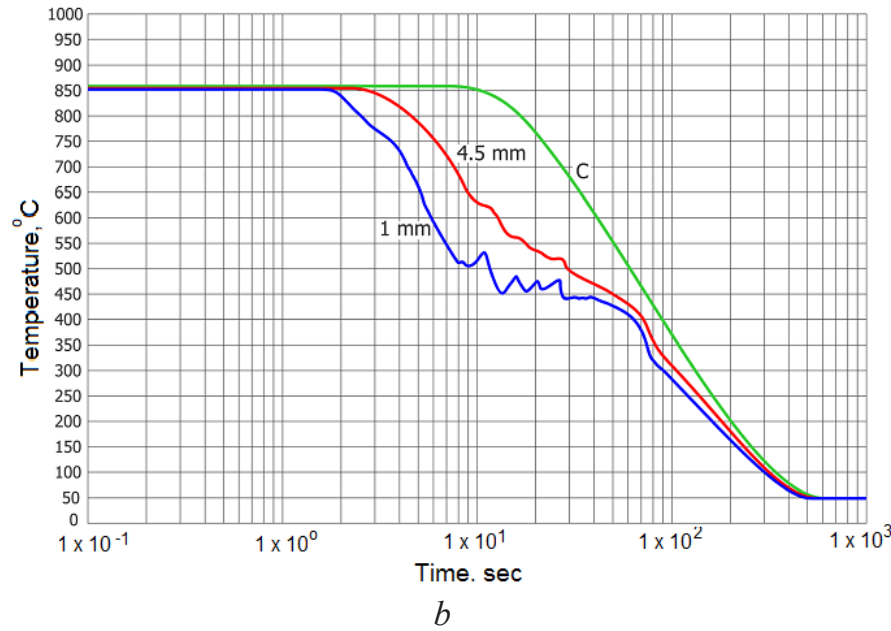

Fig. 1. Cooling curves measured by the Liscic/Petrofer probe quenched in liquid media: (a) in an accelerated mineral oil of $50^{\circ} \mathrm{C}$, without agitation; $(b)$ in a polymer solution of $35^{\circ} \mathrm{C}$, with agitation [2]) 
As seen from Fig. 1, Liscic/Petrofer probe depicted very unusual behavior of temperature in surface layer of the probe when quenching in polymer solution [2]. Initially temperature in this area drops smoothly to $500^{\circ} \mathrm{C}$ and then creates a "shoulder" where temperature maintains at the level approximately at $450{ }^{\circ} \mathrm{C}$. More information is provided in Table 2.

Table 2

Surface and core temperature versus time when quenching in a polymer solution of $35^{\circ} \mathrm{C}$

\begin{tabular}{ccccccccc}
\hline Time, $\mathbf{s}$ & $\mathbf{0}$ & $\mathbf{1}$ & $\mathbf{1 0}$ & $\mathbf{2 0}$ & $\mathbf{3 0}$ & $\mathbf{4 0}$ & $\mathbf{6 0}$ & $\mathbf{1 0 0}$ \\
\hline $\mathrm{T}_{\text {sf }},{ }^{\circ} \mathrm{C}$ & 855 & 850 & 470 & 445 & 445 & 430 & 412 & 280 \\
$\mathrm{~T}_{\text {core }},{ }^{\circ} \mathrm{C}$ & 855 & 850 & 840 & 770 & 675 & 600 & 500 & 370
\end{tabular}

Moreover, temperature within the created "shoulder" oscillates extensively at the beginning of it and oscillation stops at the end of "shoulder" [2]. Author [2] didn't explain such interesting behavior. It can be explained by self-regulated thermal process taking place during transient nucleate boiling mode $[10,11]$. The matter is that during quenching in water solution of polymers on the surface of steel parts or probes a polymeric coating is formed as shown in Fig. 2. Transient nucleate boiling process in this case takes place on the surface of the coating. Since polymeric water solution is agitated, the thickness of the coating varies versus time. As known, cooling rate depends on thickness of the coating and thermal conductivity of polymer and can be calculated using equation (2):

$$
\mathrm{v}=\frac{\mathrm{aKn}}{\left(1+2 \frac{\delta}{\mathrm{R}} \frac{\lambda}{\lambda_{\text {coat }}}\right) \mathrm{K}}\left(\mathrm{T}-\mathrm{T}_{\mathrm{m}}\right)
$$

Here $\mathrm{v}$ is cooling rate in ${ }^{\circ} \mathrm{C} / \mathrm{s}$; $\mathrm{Kn}$ is Kondratjev number; a is thermal diffusivity in $\mathrm{m}^{2} / \mathrm{s}$; $\delta$ is thickness of insulating layer; $\mathrm{R}$ is radius in $\mathrm{m} ; \lambda$ is thermal conductivity of metal in $\mathrm{W} / \mathrm{mK}$; $\lambda_{\text {coat }}$ is thermal conductivity of coating in $\mathrm{W} / \mathrm{mK} ; \mathrm{K}$ is Kondratjev form coefficient in $\mathrm{m}^{2}$; $\mathrm{T}$ is current temperature; $\mathrm{T}_{\mathrm{m}}$ is bath temperature.

Varying a thickness of the polymeric coating is a reason for temperature oscillation. Author $[13,14]$ investigated effect of polymeric coatings on initial heat flux density and temperature fields within the metallic section of the probe. Polymeric coating decreases initial heat flux density and by this way eliminates film boiling [14]. Also, as it was shown by author [14], coating increases the surface temperature of the probe during self-regulated thermal process and by this way delays martensitic transformation during transient nucleate boiling process (Fig. 2). Such unusual behavior can be used to perform austempering processes just using cold liquids [8]. It should be also noted that coating decreases temperature gradient between the core and surface metallic layer approaching the cooling in oils. For example, during quenching in oil (Fig. 1, a)) at a time 60 seconds temperature difference between surface and core is $100{ }^{\circ} \mathrm{C}$ when at a distance $1 \mathrm{~mm}$ from the surface temperature is $400{ }^{\circ} \mathrm{C}$. The same difference is observed during quenching in water polymer solution (Fig. 1, b)). Thickness of the polymeric layer is controlled by concentration of polymer in water. The above consideration shows that the great possibilities of polymers are not explored for $100 \%$ yet. Further investigations are needed which can be performed using Liscic/ Petrofer probe.

The summarizing differences between standard Inconel 600 and Liscic/Petrofer probes are provided in Table 3.

Table 3 shows that along with Inconel 600 probe the Liscic/Petrofer probe should be used for testing liquid quenchants. 
Table 3

Summarizing differences between standard Inconel 600 and Liscic/Petrofer probes

\begin{tabular}{ccc}
\hline $\begin{array}{c}\text { Inconel } 600 \text { standard probe with one } \\
\text { thermocouple at the core }\end{array}$ & $\begin{array}{c}\text { Liscic/Petrofer probe with three } \\
\text { thermocouple }\end{array}$ & Comments
\end{tabular}

It is impossible to investigate self-regulated thermal process

Due to small diameter, the initial heat flux density during immersion the Inconel 600 probe into cold liquid is almost four times larger as compared with the Liscic/ Petrofer probe resulting in different kinds of film boiling.

It is impossible to investigate accurately initial processes taking place during immersion steel parts into liquid quenchant.

Many big companies provide cooling curves and cooling rates of standard probe obtained during its testing in their liquid quenchants. It is nothing to do with such data since in many cases they are far from real steel parts quenching.

Due to simple approach in cooling curves and cooling rate obtaining, it looks like customers save time and money when using standard Inconel 600 probe.

It is impossible to investigate fundamental initial processes during quenching of steel parts heated to high temperatures.

There are nowadays in the world several thousands of small standard Inconel 600 probes in use.

Standard Inconel 600 probe $(12.5 \mathrm{~mm}$ in diameter and $60 \mathrm{~mm}$ long) is useful for laboratory tests of different oils or polymer solutions to compare their cooling ability, when testing a new delivery or developing a new sort of quenchants, as well as for monitoring of a quenching bath in respect of its deterioration.

No information on temperature field through the section of a probe.
The Liscic/Petrofer probe with accurately instrumented three thermocouple provides accurate surface temperature behavior during boiling processes.

In many cases film boiling is absent that allows generalization of experimental data.

Provides initial temperature gradients during immersion probe into liquid quenchant.

In average it provides realistic data taking place during quenching in liquid quenchants.

Due to more complicated approach, when testing Liscic/Petrofer probe, it looks like customers need to invest some additional money for testing real processes.

It is possible to investigate fundamental initial processes during immersion of steel parts into liquid quenchants.

There is only one place (the company PETROFER) which has the Liscic/ Petrofer probe and uses it for own experiments.

The experimental data obtained by Liscic/Petrofer probe are nearer to industrial processes.

Ability to measure and record the quenching intensity of all different kinds of liquid quenching media (including salt-baths at elevated temperatures), in different quenching conditions and at different quenching techniques (conventional quenching, intensive quenching, delayed quenching, martempering and austempering).
The Liscic/Petrofer probe allows determining both real HTCs and effective HTCs. Inconell 600 probe provides only effective HTCs for small diameter.

Film boiling, especially local film boiling, is undesirable since it is a reason for big distortion and non-uniform surface hardness.

The initial phase of cooling in liquid quenchants is the most important since it dictates the future history of cooling.

Based on Liscic/Petrofer probes, it is possible to modify correlation between duration of transient nucleate boiling process and size, form and thermal properties of solid material and liquid.

In fact, customers don't use $100 \%$ possibilities of their quenchants and sometimes are losing money and effectiveness.

Classical heat conductivity law of Fourier doesn't work properly during immersion of heated to high temperature steel parts into liquid quenchant.

Unfortunately, it is impossible to investigate self-regulated thermal process using standard Inconel 600 probe.

The probe of small diameter generates more easily film boiling due to higher initial heat flux density. As a result, the heat extraction dynamic from this small Inconel 600 probe (surface heat flux) is totally different from those at quenching real parts.

The Inconel 600 probe cannot be used for investigating martempering and austempering processes. 


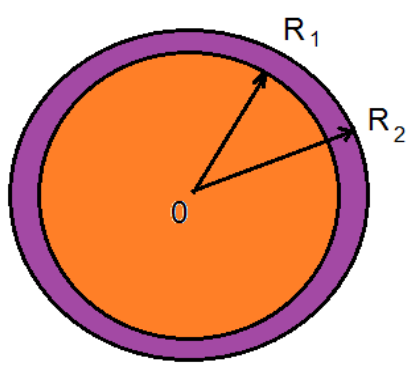

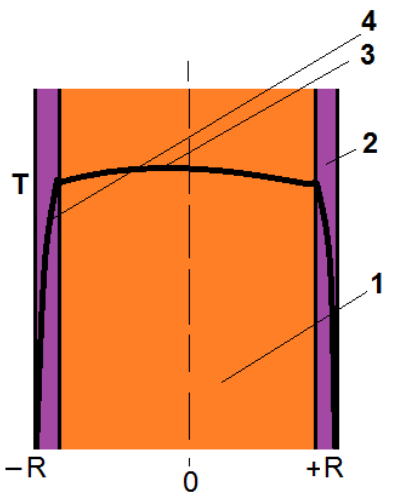

$b$

Fig. 2. Section of a coated cylindrical probe and typical temperature distribution during quenching in polymer water solution [14]:

$a$ is section of a cylinder; $b$ is temperature distribution in cylinder; 1 - heated metal,

2 - coating, 3 -temperature gradient in metal, 4 - temperature gradient in polymeric surface layer

\section{Fundamentals to be widely and carefully investigated during initial process of quenching}

It is generally assumed that during quenching of heated to $800-1000{ }^{\circ} \mathrm{C}$ steel parts, the three heat transfer modes always take place: film boiling, nucleate boiling and convection. This belief is based on classical Fourier's law which predicts an infinity heat flux density during immersion heated to high temperatures steel parts into the cold liquid. In fact, initial stage of quenching is governed by the modified Fourier law [15] which is written as:

$$
\mathrm{q}=-\lambda \nabla \mathrm{T}-\tau_{\mathrm{r}} \frac{\partial \mathrm{T}}{\partial \tau}
$$

Here $\mathrm{q}$ is heat flux density in $\mathrm{W} / \mathrm{m}^{2} ; \lambda$ is thermal conductivity in $\mathrm{W} / \mathrm{mK} ; \nabla \mathrm{T}$ is temperature gradient; $\tau_{\mathrm{r}}$ is constant of a time in sec; $\mathrm{T}$ is temperature in ${ }^{\circ} \mathrm{C}$ or $\mathrm{K}$.

The modified Fourier law generates hyperbolic heat conductivity differential equation which was widely considered and solved by authors [16-19]. According to hyperbolic equation, initial heat flux density is finite value which can be less than the first critical heat flux density and that means absence of film boiling at all. This is a theoretical conclusion. Practically, prior to start boiling process in cold liquids, a boundary layer heated to saturation temperature must be formed first. During this short time of forming boundary layer the surface temperature of probe or steel part drops immediately almost to saturation temperature and then maintains relatively a long time at this level. Experimental evidences of such phenomena were provided by French in 1928 (Table 1).

\section{Discussion}

Contemporary hardening processes require optimization liquid coolants to eliminate completely local and full film boiling processes. Optimization goes through maximizing critical heat flux densities. It means that DATABASE concerning different kinds of quenchants should include critical heat flux densities as the characteristics of a liquid. Further heat transfer coefficients should be evaluated depending on forms and sizes of steel parts. For this purpose Liscic/Petrofer probes of different sizes and forms should be prepared which is rather costly procedure. To fulfill such important task for the practice, the big companies should be as sponsors which are greatly interested in such DATABASE. To make simplified calculations, the DATABASE should provide Kondratjev numbers Kn as shown in Fig. 3. 


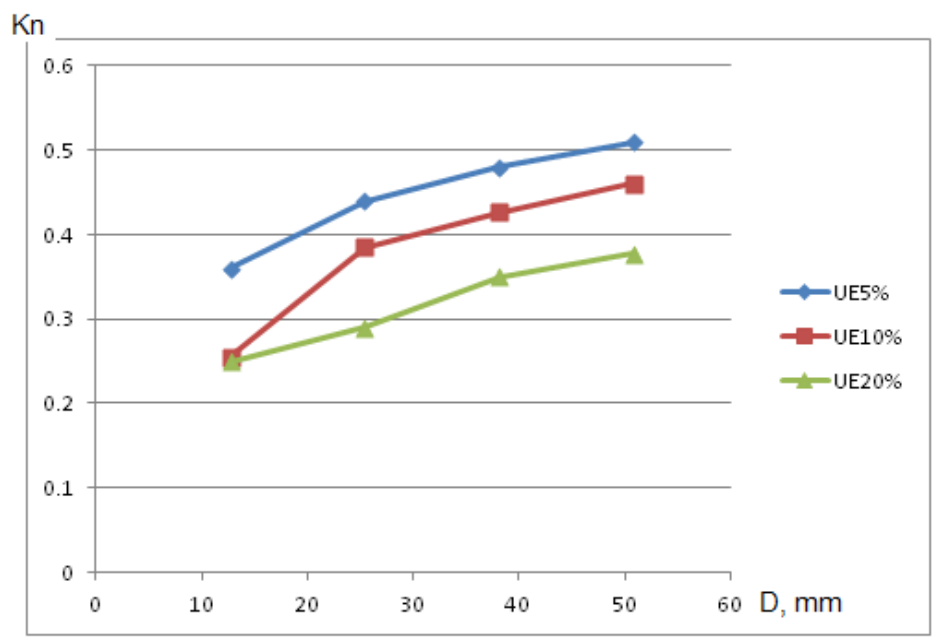

Fig. 3. Effective Kondratjev numbers Kn versus concentration of PAG in water: UE5 $\%$ is UCON E of $5 \%$ concentration at the temperature $43{ }^{\circ} \mathrm{C}$ with agitation $0.25 \mathrm{~m} / \mathrm{s}$; $\mathrm{UE} 10 \%$ is UCON E of $10 \%$ concentration at the temperature $32{ }^{\circ} \mathrm{C}$ and agitation $0.41 \mathrm{~m} / \mathrm{s}$; UE2 $\%$ is UCON E of $20 \%$ concentration at the temperature $43{ }^{\circ} \mathrm{C}$ with agitation $0.51 \mathrm{~m} / \mathrm{s}$

More information on DATABASE development and testing liquid quenchants, one can find in publication [19, 20]. Cooling characteristics of polymers are discussed in Refs [21, 22]. It should be noted that experimental data obtained by testing Liscic/Petrofer probe provide accurate results of calculations during solving inverse problem which is currently highly developed and used in practice [23, 24]. Along with the database development, the Liscic/Petrofer probe can be used by engineers to investigate deeply and widely self - regulated thermal phenomenon which is the basis for performing austempering processes in cold liquids. This new direction in heat treating industry is very promising and can bring exceptionally benefits to big companies in the world which is currently first patented in Ukraine [8]. Authors hope that many scientists in the world will be interested in investigation theoretically and experimentally the discovered self-regulated thermal process. It makes sense to start such investigations via the EC projects to involve big companies in Europe.

\section{Conclusions}

1. During quenching in water polymer solution the self-regulated thermal process on the coated surface is observed resulting in creation a temperature "shoulder" in the surface layers of a probe or quenched steel parts.

2. When carefully investigated, the polymers can be used to perform austempering processes with the use of cold polymeric solutions.

3. Oscillation of temperature in surface layers during quenching in polymers is explained by varying the thickness of a coating.

4. Insulating coating on the surface of probe or steel part increases metallic surface temperature of steel part or probe delaying martensite transformation during transient nucleate boiling process.

5. Liscic/ Petrofer probe is an excellent tool for investigation listed in 1-4 processes and can be used for testing the modified heat conductivity law of Fourier.

6. Liscic/Petrofer probe can be used also by engineers to investigate deeply and widely mentioned self-regulated thermal phenomenon during quenching in water and water salt solutions which is the basis for performing austempering processes in cold liquids.

\section{References}

[1] Liscic, B., Tensi, H. M., Luty, W. (Eds.). (1992). Theory and Technology of Quenching. Berlin: Springer, 484. doi: 10.1007/978-3-662-01596-4

[2] Liscic, B. (2016). Measurement and Recording of Quenching Intensity in Workshop Conditions Based on Temperature Gradients. Materials Performance and Characterization, 5 (1), 209-226. doi: 10.1520/ $\operatorname{mpc} 20160007$ 
[3] Kobasko, N., Aronov, M., Powell, J., Totten, G. (2010). Intensive Quenching Systems: Engineering and Design. ASTM, 252. doi: 10.1520/mnl64-eb

[4] ISO 9950:1995. Industrial quenching oils - Determination of cooling characteristics - Nickel-alloy probe test method. (1995). Geneva, Switzerland: International Organization for Standardization. Available at: https://www.iso.org/obp/ui/\#iso:std:iso:9950:ed-1:vl:en

[5] ASTM D6200-01(2017). Standard Test Method for Determination of Cooling Characteristics of Quench Oils by Cooling Curve Analysis. (2017). ASTM International, West Conshohocken, PA. doi: 10.1520/ d6200-01r12

[6] ASTM D6482-06(2016). Standard Test Method for Determination of Cooling Characteristics of Aqueous Polymer Quenchants by Cooling Curve Analysis with Agitation (Tensi Method). (2016). ASTM International, West Conshohocken, PA. doi: 10.1520/d6482-06r16

[7] ASTM D6549-06(2015). Standard Test Method for Determination of Cooling Characteristics of Quenchants by Cooling Curve Analysis with Agitation (Drayton Unit). (2015). ASTM International, West Conshohocken, PA. doi: 10.1520/d6549-06r15

[8] Kobasko, N. I. (2015, October 26). Isothermal Method for Hardening of High Carbon Steels and Irons. UA Patent No. 109935.

[9] Kobasko, N. (2016). Designing of advanced and original austempering processes based on thermal science and engineering physics approaches. EUREKA: Physics and Engineering, 2, 43-50. doi: 10.21303/2461-4262.2016.00060

[10] Kobasko, N. I. (2005). Self-regulated thermal processes during quenching of steels in liquid media. International Journal of Microstructure and Materials Properties, 1 (1), 110-125. doi: 10.1504/ijmmp.2005.008135

[11] Kobasko, N. I. (2009). Transient Nucleate Boiling as a Law of Nature and a Basis for Designing of IQ Technologies. Proceedings of the 7th IASME/WSEAS International Conference on Heat Transfer, Thermal Engineering and Environment (HTE ‘09), Moscow, 2009, August 20-22, 67-76.

[12] French, H. J. (1930). The Quenching of Steels. Cleveland, Ohio, USA: American Society for Steel Treating, 177.

[13] Kobasko, N. I. (2012). Real and Effective Heat Transfer Coefficients (HTCs) Used for Computer Simulation of Transient Nucleate Boiling Processes during Quenching. Materials Performance and Characterization, 1 (1), 1-20. doi: 10.1520/mpc-2012-0012

[14] Kobasko, N. (2017). Cooling intensity of inverse solubility polyalkylene glykol polymers and some results of investigations focused on minimizing distortion of metal components. EUREKA: Physics and Engineering, 2, 55-62. doi: 10.21303/2461-4262.2017.00294

[15] Lykov, A. V. (1967). Teoriya Teploprovodnosti (Theory of Heat Conductivity). Moscow: Vysshaya Shkola, 600 .

[16] Buikis, A., Kalis, H. (2010). Hyperbolic Heat Equation in Bar and Finite Difference Schemes of Exact Spectrum. Latest Trends on Theoretical and Applied Mechanics, Fluid Mechanics and Heat \& Mass Transfer. WSEAS Press, 142-147.

[17] Buike, M., Buikis, A., Kalis, H. (2015). Time Direct and Time Inverse Problems for Wave Energy and Steel Quenching Models, Solved Exactly and Approximately. WSEAS Transactions on Heat and Mass Transfer, 10, 31-44.

[18] Bobinska, T., Buike, M., Buikis, A. (2010). Hyperbolic Heat Equation as Mathematical Model for Steel Quenching of L-Shape Samples, Part 2 (Inverse Problem). Continuum Mechanics, Fluids, Heat. WSEAS Press, 21-26.

[19] Felde, I. (2016). Liquid quenchant database: determination of heat transfer coefficient during quenching. International Journal of Microstructure and Materials Properties, 11 (3/4), 277. doi: 10.1504/ijmmp.2016.079154

[20] Liscic, B., Singer, S., Beitz, H. (2011). Dependence of the Heat Transfer Coefficient at Quenching on Diameter of Cylindrical Workpieces. 18th International Federation for Heat Treatment and Surface Engineering, 438-449. doi: 10.1520/stp49449t

[21] Tensi, H. M., Totten, G. E., Kunzel, T. (2000). Physics and Technology of Quenching in Fluids Part I. The 12th IFHTSE Congress Proceedings, 727-730. 
[22] Totten, G. E., Bates, C. E., Clinton, M. A. (1993). Handbook of Quenchants and Quenching Technology. Materials Park, Ohio: ASM International, 507.

[23] Alifanov, O. M. (1994). Inverse Heat Transfer Problems. International Series in Heat and Mass Transfer. Berlin, Heidelberg: Springer, 348. doi: 10.1007/978-3-642-76436-3

[24] Guseynov, Sh. E. (2003). Methods of the solution of some linear and nonlinear mathematical physics inverse problems. Riga, Latvia: University of Latvia, 146.

\title{
INVESTIGATION OF THE INFLUENCE OF NANODISPERSED COMPOSITIONS OBTAINED BY PLASMOCHEMICAL SYNTHESIS ON THE CRYSTALLIZATION PROCESSES OF STRUCTURAL ALLOYS
}

\author{
Yevgen Dzhur \\ Oles Gonchar Dnirpo National University \\ 72 Gagarina ave., Dnipro, Ukraine, 49010 \\ material.ftf@gmail.com \\ Alexander Kalinin \\ SINE Prydniprovska State Academy of Civil Engineering and Architecture \\ 24 a Chernyshevsky str., Dnipro, Ukraine, 49600 \\ kalinina.dnu@gmail.com \\ Maryna Grekova \\ Yuzhnoye State Design Office \\ 3 Krivorozhskaya str., Dnipro, Ukraine, 49008 \\ marina.grekova.kbu@gmail.com \\ Michael Guchenkov \\ Yuzhnoye State Design Office \\ 3 Krivorozhskaya str., Dnipro, Ukraine, 49008 \\ gtpmik@gmail.com
}

\begin{abstract}
The state of the problem of stabilizing the structure, improving the quality and properties of structural alloys is studied. To solve the problem, it is proposed to modify melts of low-alloyed alloys with nanodispersed compositions obtained by plasma-chemical synthesis. Process technological parameters are developed. Nanopowders of carbide and carbonitride class $\mathrm{SiC}$ and Ti (C, N) with a size of 50...100 nm are obtained. The crystallographic parameters of the nanocompositions and the specific surface are determined, and the dependency curves are plotted. The macro- and microstructure of structural steels and alloys was studied before and after the modification. A significant (in 2...3.5 times) grain refinement and stabilization of the alloy structure as a result of nanopowder modification of titanium carbonitride have been achieved. Thermodynamic calculations of the dimensions of crystalline seeds during the crystallization of steels and alloys are carried out. A complex criterial estimation of the efficiency of nanodispersed compositions in a steel melt is proposed. The features of crystallization and structure formation of modified structural steels are studied. The obtained results are of theoretical and practical importance for production of critical parts from structural steels and high-quality alloys.
\end{abstract}

Keywords: structural steel, aluminum alloy, nanodispersed compositions, plasma-chemical synthesis, crystallization, structure.

\section{Introduction}

The field of study of nanodispersed materials is the most rapidly developing in modern materials science, since the production of finely dispersed structures contributes to a fundamental 